\title{
Halyomorpha halys (Stal) mücadelesinde ışık ve feromon tuzaklarının etkinliliklerinin araştırılması
}

\section{The investigation of effectiveness of light and pheromone traps on control of Halyomorpha halys (Stal)}

\section{Temel GÖKTÜRK}

Artvin Çoruh Üniversitesi Orman Fakültesi Orman Mühendisliği Bölümü, Artvin, Türkiye

Eser Bilgisi / Article Info

Araştırma makalesi / Research article

DOI: 10.17474/artvinofd.747194

Sorumlu yazar / Corresponding author Temel GÖKTÜRK

e-mail: temel.gokturk@gmail.com

Geliş tarihi / Received

02.06.2020

Düzeltme tarihi / Received in revised form

10.06.2020

Kabul Tarihi / Accepted

28.06.2020

Elektronik erişim / Online available

02.09.2020

\section{Anahtar kelimeler:}

İstilacı tür

Kahverengi kokarca böceği

Feromon tuzağı

Işık tuzağı

Türkiye

\section{Keywords:}

Invasive species

Brown marmorated stink bug

Pheromone trap

light trap

Turkey

\begin{abstract}
Özet
Halyomorpha halys (Kahverengi kokarca) (Stål, 1855) (Hemiptera: Pentatomidae) Türkiye için yeni istilacı bir tür olmasına rağmen, kısa bir sürede Doğu Karadeniz Bölgesi'nde hızla yayılma imkanı bulmuştur. Yayılış gösterdiği diğer ülkelerin en önemli zararlısı konumunda olan bu türün, ülkemizde ise Doğu Karadeniz Bölgesi'nde mısır, fasulye, fındık ve kivi bitkilerinde yoğun olarak beslendiği gözlemlenmiştir. $H$. halys'ın mücadelesinde henüz tam bir entegre mücadele stratejisi oluşturulmamıştır. Bu kapsamda en çok kullanılan yöntem kimyasal mücadele olmasına rağmen, biyolojik, biyoteknik mücadeleler konusunda çalışmalar devam etmektedir. Bu çalışmada da feromon ve ışık tuzaklarının etkinliği araştırılmaya çalışılmıştır. İçerilerinde PHEROCON ${ }^{\circledR}$ feromonu bulunan tuzaklar ve ışık tuzakları, 2019 yılının Nisan-Ekim aylarında asılı olarak kalmış ve her hafta düzenli olarak kontrolleri yapılmıştır. Yapılan kontroller sonucu bir ışık tuzağına 30.12 (0-85), feromon tuzağına ise 24.72 (1-69) H. halys'ın erginlerinin düştüğü tespit edilmiştir. Araştırmanın yapıldığı süre boyunca (27 hafta) bir feromon tuzağına toplam 618, bir ışık tuzağına da 753 adet $H$. halys ergini düşmüştür. Işık tuzaklarına ve feromon tuzaklarına düşen böcek sayıları karşılaştıııldığında, erken dönemde her iki tuzağa da düşen böcek sayısının birbirlerine yakın olduğu saptanırken, orta dönemde ışık tuzaklarında, geç dönemde ise feromon tuzaklarında yakalanan böcek sayılarını daha fazla olduğu gözlemlenmiştir. Bu sonuçlara göre, $H$. halys'a karşı yürütülecek mücadelede, ışık ve feromon tuzaklarının birlikte kullanılmaları, zararlı popülasyonunu azaltacağı kanısına varılmıştır.
\end{abstract}

\begin{abstract}
Halyomorpha halys (Brown marmorated stink bug) Stål, 1855) (Hemiptera: Pentatomidae) although there is a new invasive species for Turkey in the short time it has rapidly spread in the Eastern Black Sea Region. The economic harm of this species is the most important pest of other countries. H.halys has been observed that it feeds heavily on corn, bean, hazelnut and kiwi plants. In the fight of H.halys, a complete integrated control strategy (IPM) has not been developed yet. Although the most commonly used chemical control in this context, studies continues on biological and biotechnical control. In this study, the effectiveness of pheromones and light traps were tried to be investigated. The light traps and pheromone traps with PHEROCON ${ }^{\circledR}$ pheromones remained suspended in AprilOctober 2019 and were regularly checked every week. As a result of the controls, it was determined that adults of $30.12(0-85)$ in one light trap and 24.72 (1-69) in pheromone trap of $H$. halys. During the study period ( 27 weeks), a total of $618 \mathrm{H}$. halys adolescents fell to a pheromone trap and 753 adolescents to a light trap. According to these results, it was concluded that the use of light and pheromone traps together would decrease the harmful population in the control against $H$.halys.
\end{abstract}

\section{Giriş}

İstilacı türler gerek ekosistemi gerekse biyo-çeşitliliği olumsuz olarak etkileyerek, önemli derecede ekonomik kayıplara neden olabilmektedirler (Pysek ve Richardson 2010, Simberloff ve ark. 2013). İstilacı türler, geldikleri yeni ülkelerde doğal düşmanlarının bulunmayışı, daha önceki yaşadığı ekosistemde beslendiği konukçulara ilave olarak alternatif ve daha cazip yeni konukçular bulmaları ve ayrıca, uygun iklim koşullarından dolayı kısa zamanda adapte olarak, epidemik boyuta ulaşabilmektedir
(Pimentel ve ark. 2000). İstilacı türlerden biri olan Halyomorpha halys (Kahverengi kokarca) (Stål 1855) (Hemiptera: Pentatomidae)'ın ana vatanı Doğu Asya (Çin, Japonya, Tayvan, Kore)'dır ve 1998 yılından sonra Amerika Birleşik Devletleri başta olmak üzere Asya ve Avrupa'da yüzlerde ülkeye yayılmıştır (Rider 2006, Mityushev 2016, Gapon 2016, Simov 2016, Faundez ve Rider 2014). H.halys, hızlı bir yayılma kabiliyetine sahip istilacı ve oldukça da zararlı bir böcek türüdür (Wiman ve ark. 2015). Türkiye'deki varlığı 2017 yılında İstanbul'da (Çerçi ve Koçak 2017) ve Artvin'de (Göktürk ve ark. 2018) 
tespit edilen H.halys, 2020 yılına gelindiğinde Kemalpaşa, Hopa, Arhavi (Artvin), Fındıklı, Ardeşen (Rize) ilçelerinde yoğun olmak üzere Trabzon, Giresun ve Ordu illerine kadar yayıldığı tespit edilmiştir (Göktürk ve Tozlu 2019).

Türkiye'de "Kahverengi kokarca" isminden başka "Kahverengi pis kokulu böcek" olarak da isimlendirilen bu zararlı pentatomid türünün erginleri, koyu kahverengi renkte ve 12-17 mm uzunluğunda, antenleri kısmen soluk beyaz renkli, 4. ve 5 . segmentleri hariç diğerleri siyah, bacakları kırmızımsı-sarı renklidir. Yumurtalar yaklaşık 1.6 $\mathrm{mm}$ uzunluğunda ve $1.3 \mathrm{~mm}$ çapında, elips şeklinde ve açık yeşildir. Beş nimf dönemi geçirirler. Nimflerin ilerleyen dönemlerinde pronotumları üzerinde dikenlerin bulunması ve koyu kırmızı gözlere sahip olması en karakteristik özellikleridir (Hoebeke ve Carter 2003).

H. halys, sıcaklık ve fotoperiyuma bağlı olarak yılda 1-5 döl verebilse de (Niva ve Takeda 2003, Lee 2015), Doğu Karadeniz Bölgesi'nde, Artvin ilinde yılda çoğunlukla 1, bazen de sahil kısımlarında 2 döl vermektedir. Sıcaklığa bağlı olarak; 1. döl zamanı Nisan ayının 2. Yarısı, 2. döl zamanı ise Ağustos ayında olmaktadır. Dişiler yılda bir kaç kez çiftleşmekte ve ömürleri boyunca yumurta bırakmaya devam ettiklerinden yumurtlama süresi aylarca sürebilmektedir. Kışı ergin olarak kuytu alanlar, eski binalar, çatı araları, ahırlar, ağaç kovukları gibi uygun yerlerde geçiren bireyler Nisan ayının ikinci yarısında kışlama alanlarını terk ederek, 20-30'lu gruplar halinde (toplam 100-220 yumurta) yumurtalarını bırakmaktadır. Yumurtalardan 4-5 günde çıkan ilk dönem nimfler, beş nimf dönemi geçirdikten sonra ergin olmaktadır. Erginlerin en yoğun görüldüğü dönem Ağustos ayı olup, sıcaklığa bağlı olarak Eylül sonundan itibaren kışlaklara çekilmeye başlamaktadır (Göktürk ve ark. 2018, Göktürk ve Tozlu 2019).

H. halys, polifag olarak beslenen bir tür olup, çok fazla sayıda değişik bahçe ve süs bitkilerinde zaman zaman ekonomik derece zararlara yol açabilmektedir. En önemli konukçuları arasında ahududu, akçaağaç, armut, ateş dikeni, bakla, bezelye, biber, böğürtlen, ceviz, dut, elma, erik, fasulye, fındık, hanımeli, leylak, kayısı, üzüm, kiraz, kivi, mısır, söğüt, şeftali, turunçgiller, Trabzon hurması, soya fasulyesi, şeker pancarı, kelebek çalısı ve birçok yabancı ot türü yer almaktadır (Bernon 2004, Kiritani 2007, Hamilton 2009, Leskey ve ark. 2012b, Lee ve ark. 2013, Göktürk ve Tozlu 2019).

$H$. halys'ın ergin ve nimfleri konukçu bitkilerin öz suyunu emerek zararlı olmaktadır. Meyve ile beslenmesi sonucunda meyvede yara izleri, çukurlar, şekilsizlikler ve renk değişimleri meydana gelmekte, böceğin beslenme esnasında salgıladığı salgılar meyvede acılaşma ve taşlaşmaya neden olabilmektedir (Hamilton 2009, Leskey ve ark. 2012a,b, Costi ve ark. 2017, Rice ve ark. 2014, Scheihing ve ark. 2016). Bu zararlı tür, Amerika Birleşik Devletleri, Avrupa ve Gürcistan'da meyve ve sebzelere verdiği zarar sonucu milyonlarca dolarlık ekonomik kayba neden olmuştur (Bernon 2004, Leskey ve ark. 2012a, Murvanidze ve ark. 2018). Doğu Karadeniz Bölgesi'nde kısa bir süre olmasına rağmen Artvin ilindeki kivi alanlarında yaptığı zararı hissedilir hale gelmiştir ve her an salgın yapma riskini de taşımaktadır.

H. halys'ın mücadelesinde yaygın olarak kimyasallar kullanılmaktadır (Leskey ve ark. 2012a, 2014). Kimyasal ilaçların yararlı eklembacaklılar ve tozlaşmayı gerçekleştiren eklembacaklılar üzerinde olumsuz etkilerinin bulunması, $H$. halys'n belirli bir müddet sonra bunlara direnç geliştirmesi alternatif mücadele yöntemleri arayışını zorunlu kılmıştır (Holtz ve Kamminga 2010). Biyolojik mücadele kapsamında Telenomus podisi, Trissolcus sp. ve T.halyomorphae (Hymenoptera: Scelionidae)'nin, $H$. halys'। parazitlediği belirlense de popülasyon seviyeleri üzerinde çok az etkiye sahip olduğu belirtilmektedir (Haye ve ark. 2015). H. halys'ın popülasyon yoğunluğunun belirlenmesi ve kitlesel yakalanmasında kullanılan bir diğer yöntem de feromon tuzaklarıdır (Adachi ve ark. 2007, Weber ve ark. 2014, Khrimian ve ark. 2014). Rice ve ark. (2017), arazide yaptıkları çalışmaların sonucunda hem yüksek hem de düşük yoğunluklu populasyonlarda $H$. halys aktivitesin tespit etmek için ışı ve feromon tuzakların kullanılabileceğini belirtmektedirler. Nielsen ve ark. (2013) pentatomidlerin siyah ışık tuzağına yakalandığın ve bu tuzakların iyi bir izleme aracı olabileceğini bildirmektedirler. Son yıllarda, tuzak tasarımları, renkler, feromon preparatları, yayılma stratejileri ve yakalama mekanizmaları başta olmak üzere, $H$. halys'ı izlemek için 
çeşitli çalışmalar yapılmıştır (Leskey ve ark. 2015, Weber ve ark. 2017). Bu çalışmalara dayanarak, oluklu plastikten yapılmış siyah piramit tuzağı standart tuzak haline gelmiş ve agregasyon feromonu (metil $(2 \mathrm{E}, 4 \mathrm{E}, 6 \mathrm{Z})$-dekatrienoat (MDT) ile kombinasyonu) mücadele ve izlemede kullanılabileceği belirtilmiştir (Weber ve ark. 2014, Leskey ve ark. 2015). Feromon tuzakları ile $H$. halys'ın biyolojisi tespit edilerek mücadele takvimi oluşturulabilmektedir (Short ve ark. 2017).

Doğu Karadeniz Bölgesi'nde 2018 tarihinde Samsun, Ordu, Giresun, Trabzon, Rize ve Artvin illerinin 49 ilçesinde $H$. halys'a karşı feromon tuzakları asılarak, survey çalışması yürütülmüş ve bölgedeki yayılışı belirlenmeye çalışılmıştır (Ak ve ark. 2019). Türkiye için henüz yeni bir tür olmasına rağmen yayılış ve zararını hızla gerçekleştiren bu türe karşı ışık ve feromon tuzaklarının etkinliklerini belirlemek amacıyla gerçekleştirilen bu çalışmada, $H$. halys erginlerinin feromon ve ışık tuzaklarına düşsme oranları araştırımıştır.

\section{MATERYAL VE YÖNTEM}

Bu çalışmanın ana materyalini, Artvin ili, Arhavi ilçesinde tarım ve orman alanlarında zarar oluşturan $H$. halys'ın ergin bireyleri oluşturmaktadır. Çalışma, 2019 yılında Arhavi bölgesindeki kivi bahçesinde yapılmıştır. Arazi çalışmaları, erginlerin toplanmasına yönelik çalışmalardan oluşmaktadır. Böceklerin toplanmasında içlerinde PHEROCON ${ }^{\circ}$ feromonu, feromon tuzakları olarak 4 adet 10 litrelik plastik su bidonları ve 4 adet ışık tuzağı kullanılmıştır. Çalışmada kullanılan ışık tuzakları, SAHRA Çevre Sağlığı Ve Ormancılık A.Ş. tarafından sağlanmıştır.
Böceğin biyolojisi dikkate alınarak, tuzaklar, arazide güney-güneydoğu yönünde Nisan aynının son haftasında yerleştirilmiş ve Kasım ayına kadar kontrol edilmiştir. Feromon tuzakları 1.5-2 metre yükseklikteki kivi ağaçlarının tellerine asılmıştır. Işık tuzakları ise feromon tuzakları arasına yerleştirilmiştir. Işık tuzakları akşam saat 21:00-06:00 arası faal duruma getirilmiştir. Çalışma alanı seçilirken en yakın ışık kaynağına en az $50 \mathrm{~m}$ mesafede olan alanlar seçilmiştir. Asılan tuzaklar 7-8 gün arayla kontrol edilmiş, tuzaklara düşen böcek sayıları dikkatlice not edilmiştir. Feromon tuzaklarının feromon preparatları 4 haftada bir yenisiyle değiştirilmiştir. Elde edilen verilerin karşılaştırılmasında Bağımsız iki Örnek t-Testi kullanılmıştır.

\section{BULGULAR}

Işık tuzağına yakalanan $H$. halys erginlerinin ortalaması 30.12 (0-85) olarak saptanırken, feromon tuzağına yakalanan erginlerin ortalaması 24.72 (1-69) olarak tespit edilmiştir (Şekil 1). Tuzakların asılmasını müteakip yapılan kontroller sonucunda her hafta belli oranda böceğin ışık tuzağına düştüğü görülmüştür. Tüm sezon boyunca (27 hafta) yapılan kontrollerde bir feromon tuzağına 618 , bir ışık tuzağına ise 753 adet $H$. halys ergininin düştüğü gözlemlenmiştir. Vejetasyon boyunca toplam yakalanan H. halys ergin miktarı feromon tuzaklarında 2472, ışık tuzaklarında ise 3012 olarak tespit edilmiştir. Yapılan istatistiksel analizler sonucunda dönemsel olarak ışık tuzaklarına yakalanan birey sayısı ile feromon tuzaklarına yakalanan birey sayısı arasında anlamlı bir farklılık bulunmuştur (Çizelge 1) (Bağımsız ìki Örnek t-Testi; $p<0.05)$.

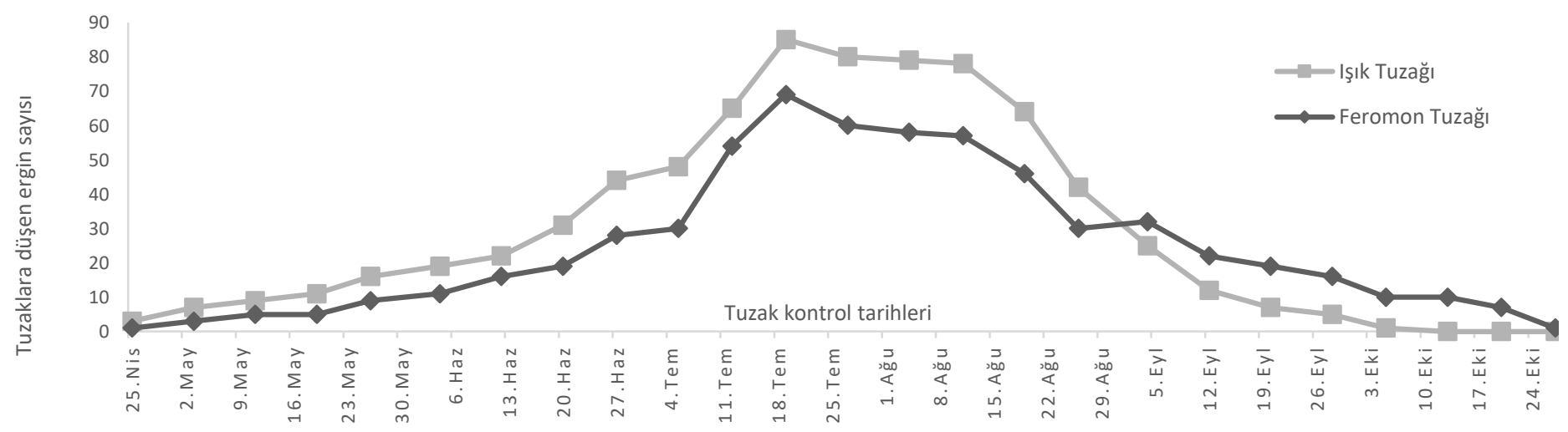

Şekil 1. Feromon ve Işık tuzaklarına düşen böceklerin haftalık kontrol sayıları 
Nisan sonundan itibaren çalışma alanından alınan veriler incelendiğinde, ışık ve feromon tuzaklarına düşen böcek miktarları birbirine yakın olduğu gözlemlenmiştir. Yakalanan birey sayısı Haziran ayının 2. haftasından sonra artış göstermiş; Temmuz ayında en yüksek orana ulaşmıştır. Eylül ayından başlayan düşüş Ekim ayının son haftası son bulmuştur (Şekil 1).

Çizelge 1. Feromon ve Işık tuzaklarına düşen böceklerin t-testine göre karşılaştırılması

\begin{tabular}{lccc}
\hline Tuzak Tipi & Aritmetik ortalaması & T değeri & P değeri \\
\hline Feromon Tuzağı & 618 & 19.222 & 0.0011 \\
Işık Tuzağı & 753 & & \\
\hline
\end{tabular}

Işık tuzaklarına hedef olmayan bazı diğer böcek türleri de düşmüştür. Feromon tuzaklarında ise hedef dışı türlere rastlanılmamıştır. Yağmurlu haftalarda hem feromon hem de ışık tuzaklarına düşen $H$. halys sayısında azalma olduğu saptanmıştır.

Işık tuzaklarında ve feromon tuzaklarında yakalanan böcek sayıları karşılaştırıldığında, erken dönemde her iki tuzağa da düşen böcek miktarları birbirine yakınken, orta dönemde ışık tuzaklarının, geç dönemde ise feromon tuzaklarının yakalama oranları daha fazla olmuştur. Değerlendirilen verilerden Nisan-Haziran döneminde ışık tuzaklarına ve feromon tuzaklarına yakalanan birey sayısı birbirine yakın iken, Haziran-Ağustos döneminde ışık tuzağına, Eylül-Kasım döneminde de feromon tuzaklarına düşen ergin sayılarının artış gösterdikleri tespit edilmiştir.

\section{TARTIŞMA VE SONUÇ}

İstilacı ve egzotik böcek türlerinin tarımsal üretimde oluşturdukları kayıplar oldukça fazladır. Hatta bu kayıplar, ekolojik şartlara ve uygulanan tarım sistemlerine göre zaman zaman artmakta ve ciddi boyutlara ulaşabilmektedir. Türkiye'de 2017 yılından beri görülen $H$. halys, özelikle Doğu Karadeniz sahil şeridini tehdit etmektedir. 2019 yılı itibari ile böceğin Giresun-Espiye'ye kadar yayıldığının gerçekleştiği dikkate alındığından önümüzdeki yıllarda Samsun’a kadar yayılış göstereceği tahmin edilmektedir. Yoğun olarak Artvin (Kemalpaşa, Hopa, Arhavi) ve Rize (Fındıklı, Ardeşen)'de bulunsa da diğer illerde de ileride popülasyon artışı yapması muhtemeldir. $H$. halys'ın ana konukçuları arasında yer alan fındığın bölgenin ekonomisinde çok önemli bir yere sahip olması ve ciddi gelir getiren bir ürün olması, ileride oluşabilecek tehlikenin boyutunu arttırmaktadır. Özellikle Giresun fındığının ince kabuklu olması $H$. halys'ın zarar oranını daha da arttıracaktır.

Geniş spektrumlu insektisitlerin sıkça kullanılması H. halys yönetimi için ana araç olmaya devam etmektedir (Leskey ve ark. 2012b, Lee ve ark. 2013, Blaauw ve ark. 2014). Oysa bu zararlı türe karşı tek bir mücadele yöntemi ile karşı koymak çok zordur. Bundan dolayı entegre mücadele stratejisi geliştirilerek, mücadele edilmelidir. Zararlının yayılış gösterdiği alanlar çay bahçeleri ile bitişik kivi alanları olduğundan bu alanlarda kimyasal mücadele yapılması yasaktır. Bu zararlı istilacı böcek türüne karşı oluşturulacak mücadele takviminde kimyasal, mekanik, biyoteknik mücadeleye ilaveten ışık tuzaklarının da kullanılması mücadeleye katkı sağlayacaktır.

H. halys'ın mücadelesine yönelik yapılan bu çalışmada asılan ışık ve feromon tuzaklarıyla belli oranlarda ergin yakalanmıştır. Nielsen ve Hamilton (2013) feromon ve ışık tuzaklarına yönelik yaptıkları çalışmada, feromon tuzaklarının aksine ışık tuzaklarının her iki cinsiyeti de aynı oranda yakaladıklarını ifade etmişlerdir. Leskey ve ark. (2015) yaptıkları feromon denemelerinde bir feromon tuzağına haftada maksimum $57 \mathrm{H}$. halys erginin düştüğünü belirtmektedirler. Yapılan bu çalışmada ise feromon tuzağına en fazla $69 \mathrm{H}$. halys ergini düşmüştür. Weber ve ark. (2014)'nında tespit ettiği gibi erken dönemde feromon tuzaklarının yakalama oranları düşük olmasına rağmen populasyon yoğunluğunun fazla olduğu Ağustos ayında yakalama maksimum düzeye ulaşmıştır. Sonbaharda feromon tuzaklarının yakalama oranı da ışık tuzaklarından fazla olmuştur. Bunun nedeninin sıcaklık olduğu tahmin edilmektedir. Çünkü ışık tuzaklarının yoğun yakalama gösterdiği geceler çoğunlukla sıcak ve yağışın olmadığı geceler olmuştur. Nilsen ve ark. (2013)'nın da tespit ettikleri gibi ışık tuzaklarına düşme erken dönemde populasyon yoğunluğu az iken de olmaktadır.

Işık tuzaklarının etki alanı feromon tuzaklarından fazladır. Ancak ışık tuzakları sadece gece çekicidir. Gece sıcaklık dereceleri $15{ }^{\circ} \mathrm{C}$ 'nin altında olduğunda $H$. halys erginleri 
uçmayacaktır (Lee ve Leskey 2015). Rice ve ark. (2017) Işık tuzakları ile yaptıkları çalışmada geç dönemlerde tuzaklara düşen ergin sayısında önemli derece azalma olduğunu, feromon tuzaklarına ise geç dönemde daha fazla birey düştüğünü belirtmektedirler. Feromon tuzakları, sezon sonunda türlerin izlenmesinde ve yakalanmasında daha etkilidir. Yapılan bu çalışmada da geç dönemde ışık tuzaklarının yakalama oranı düşmüştür. Işık tuzakları ve feromon tuzakları kombine bir şekilde kullanılırsa etki oranının artacağı kanısı hakim olmuştur. Tuzakların alana asılış zamanı da önem arz etmektedir. Tuzaklar alana ergin dönemi başlamadan bir hafta önce asılması durumunda erginlerin yumurta koymadan önce yakalayabilmek mümkün olacaktır ve ergin dişilerin yumurta koymalarının engellenmesiyle de popülasyonunun bu şekilde düşürülmesi sağlanacak, zararları da azaltılmış olunacaktır. Ancak, doğal denge ve biyo-çeşitlilik açısından popülasyonunun tamamen ortadan kaldırıması da istenmeyen bir durumdur.

Işık tuzakları olsun feromon tuzakları olsun $H$. halys'a karşı yapılacak mücadele çalışmalarında bireysel olduğunda etkili olmaz. Bundan dolayı mücadele çalışmaları mümkünse geniş alanda yapılmalıdır. Sadece küçük bir alandan toplanan erginlerle populasyon seviyesinin düşürülmesi mümkün görülmemektedir.

Amerika Birleşik Devletlerinde feromon tuzaklarına bir hafta içerisinde düşen böcek miktarına göre bölge için risk durumu belirlenmiştir. Tuzaklara 10 ve daha fazla $H$. halys ergini düşmesi durumunda yüksek riskli, 5-10 adet $H$. halys ergini düşmesi durumunda orta riskli, 0-2 adet düşmesi durumunda düşük riskli olarak nitelendirilmektedir. Çalışma alanında tuzaklara ortalama 0-85 adet ergin düştüğü dikkate alındığında böceğin populasyon durumu açısından bölgenin riskli olduğu söylenebilir.

Sonuç olarak, bu çalışma Türkiye'de $H$. halys'ın kontrolünde ışık tuzaklarının etkisini belirlemeye yönelik yapılan ilk çalışmadır. Çalışmada elde edilen veriler, $H$. halys'a karşı alınacak önlemlere ve gelecekteki çalışmalara destek olacaktır.

\section{KAYNAKLAR}

Adachi I, Uchino K, Mochizuki F (2007) Development of a pyramidal trap for monitoring fruit-piercing stink bugs baited with Plautia crossota Stali (Hemiptera: Pentatomidae) aggregation pheromone, Appl. Entomol. Zool., 42: 425-431.

Ak K, Uluca M, Aydin Ö, Gokturk T (2019) Important invasive species and its pest status in Turkey: Halyomorpha halys (Stål) (Heteroptera: Pentatomidae). Journal of Plant Diseases and Protection, 126: 401-408.

Bernon G (2004) Biology of Halyomorpha halys, the Brown Marmorated Stink Bug (BMSB). Final Report, USDA APHIS CPHST, $17 \mathrm{pp}$.

Blaauw BR, Polk D, Nielsen AL (2014) IPM-CPR for peaches: incorporating behaviorally-based methods to manage Halyomorpha halys and key pests in peach, Pest Manag., 71 (11): 1513-22.

Çerçi B, Koçak Ö (2017) Further contribution to the Heteroptera (Hemiptera) fauna of Turkey with a new synonymy. Acta Biologica Turcica, 30 (4): 121-127.

Faúndez El, Rider DA (2014) Nuevos registros de Pentatominae Leach, 1815 en Chile (Hemiptera: Heteroptera: Pentatomidae), Boletín de la Sociedad Entomológica Aragonesa, 55: 159-162.

Gapon D (2016) First records of the brown marmorated stink bug Halyomorpha halys (Stål, 1855) (Heteroptera, Pentatomidae) in Russia, Abkhazia, and Georgia. Entomol. Rev. 96: 1086-1088.

Gokturk T, Tozlu G (2019) An important agricultural pest for Turkey: invasive species Halyomorpha halys. In: Proceedings of International Black Sea Coastline Countries Symposium, May 2-5, Batumi / Georgia, pp. 283-297.

Göktürk T, Burjanadze M, Supatashvili A (2018) Artvin ve Çevresinde Halyomorpha halys (Hemiptera: Pentatomidae)'ın Biyolojisi ve Zararı. III. Türkiye Orman Entomolojisi ve Patolojisi Sempozyumu Bildiri Kitabı, 10-12 Mayıs, Artvin. s.11.

Hamilton CG (2009) Brown marmorated stink bug. American Entomologist, 55: 19-20.

Haye T, Fischer S, Zhang J, Gariepy T (2015) Can native egg parasitoids adopt the invasive Brown marmorated stink bug, Halyomorpha halys (Heteroptera: Pentatomidae), in Europe?, J. Pest Sci., 88: 693-705.

Hoebeke ER, Carter ME, (2003) Halyomorpha halys (Stål) (Heteroptera: Pentatomidae): a polyphagous plant pest from Asia newly detected in North America. Proceedings of the Entomological Society of Washington, 105: 225-237.

Khrimian A, Zhang A, Weber DC, Ho H-Y, Aldrich JR, Vermillion KE, Siegler MA, Shirali S, Guzman F, Leskey TC (2014) Discovery of the aggregation pheromone of the brown marmorated stink bug (Halyomorpha halys) through the creation of stereoisomeric libraries of 1-bisabolen-3-ols. Journal of Natural Products 77: 1708-1717.

Lee DH, Leskey TC (2015) Flight behavior of foraging and overwintering Brown marmorated stink bug, Halyomorpha halys (Hemiptera: Pentatomidae). Bulletin of Entomological Research, 105: 566-573.

Lee DH (2015) Current status of research progress on the biology and management of Halyomorpha halys (Hemiptera: Pentatomidae) as an invasive species. Appl. Entomol. Zool., 50: 277-290.

Lee DH, Short BD, Joseph SV, Bergh JC, Leskey TC (2013), Review of the biology, ecology and management of Halyomorpha halys (Hemiptera: Pentatomidae) in China, Japan and the Republic of Korea. Environ. Entomol., 42:627-641.

Leskey TC, Lee DH, Short BD, Wright SE (2012a) Impact of insecticides on the invasive Halyomorpha halys (Stål) (Hemiptera: 
Pentatomidae): analysis on the insecticide lethality. Journal of Economic Entomology, 105: 1726-1735.

Leskey TC, Short BD, Butler BR, Wright SE (2012b) Impact of the invasive Brown marmorated stink bug, Halyomorpha halys (Stål), in mid- Atlantic tree fruit orchards in the United States: case studies of commercial management. Psyche, doi:10.1155/2012/535062.

Leskey TC, Agnello A, Bergh JC, Dively GP, Hamilton GC, Jentsch P, Khrimian A, Krawczyk G, Kuhar TP, Lee DH, Morrison WR (2015) Attraction of the invasive Halyomorpha halys (Hemiptera: Pentatomidae) to traps baited with semiochemical stimuli across the United States. Environmental Entomology, 44: 746-756.

Leskey TC, Short BD, Lee DH, (2014) Efficacy of insecticide residues on adult Halyomorpha halys (Stal) (Hemiptera: Pentatomidae) mortality and injury in apple and peach orchards. Pest Manag. Sci., 70: 1097-1104.

Mityushev IM (2016) First Report of the Brown Marmorated Stink Bug, Halyomorpha halys Stål, in the Russian Federation. In: Baranchikov Yu. N. (Ed.) Monitoring and biological control methods of woody plant pests and pathogens: from theory to practice. Proceedings of International conference. Moscow, April 18-22, 2016. Institute of Forest, RAN, Krasnoyarsk, pp. 147-148.

Nielsen AL, Holmstrom K, Hamilton GC, Cambridge J, Ingerson-Mahar J (2013) Use of black light traps to monitor the abundance and spread of the Brown marmorated stink bug. Journal of Economic Entomology, 106: 1495-1502.

Niva CC, Takeda M (2003) Effects of photoperiod, temperature and melatonin on nymphal development, polyphenism and reproduction in Halyomorpha halys (Heteroptera: Pentatomidae). Zool. Sci., 20: 963-970.

Pimentel DL, Lach R, Zuniga Morrison D, (2000) Environmental and economic costs of nonindigenous species in the United States. Bioscience, 50 (1): 53-65.

Pysek P, Richardson DM (2010) Invasive species, environmental change and management, and health. Annu. Rev. Environ. Resour., 35: 25-55.
Rice KB, Bergh JC, Bergmann EJ et al. (2014) Biology, ecology and management of brown marmorated stink bug (Hemiptera: Pentatomidae). Journal of Integrated Pest Management 5: 1-13.

Rice KB, Cullum JP, Wiman NG, Hilton R, Leskey TC (2017) Halyomorpha halys (Hemiptera: Pentatomidae) response to pyramid traps baited with attractive light and pheromonal stimuli. Fla. Entomol., 100: 449-453.

Rider DA (2006) Family Pentatomidae Leach, 1815, in Catalogue of the Heteroptera of the Palaearctic Region Vol. 5. II, Ed. by Aukema, B. and Rieger, C. (The Netherlands Entomological Society, Wageningen, 233-402.

Scheihing B, Estes KA, Kenneth W, McCravy KW (2016) First record of the invasive pest, Halyomorpha halys (Hemiptera: Pentatomidae), in McDonough County, and its current distribution in Illinois. Transactions of the Illinois State Academy of Science, 10, 1-25.

Short BD, Khrimian A, Leskey TC (2017) Pheromone-based decision support tools for management of Halyomorpha halys in apple orchards: Development of a trap-based treatment threshold. J. Pest Sci., 90:1191-1204.

Simberloff D, Martin JL, Genovesi P (2013) Impacts of biological invasions: what's what and the way forward. Trends Ecol. Evol., 28: 58-66.

Simov N (2016) The invasive brown marmorated stink bug Halyomorpha halys (Stal 1855 (Heteroptera: Pentatomidae) already in Bulgaria. Ecol. Montenegrina, 9: 51-53.

Weber DC, Leskey TC, Walsh GC, Khrimian A (2014) Synergy of aggregation pheromone with methyl (E,E,Z)-2,4,6-decatrienoate in attraction of Halyomorpha halys (Hemiptera: Pentatomidae). Journal of Economic Entomology, 107: 1061-1068.

Weber DC, Morrison WR, Khrimian A, Rice KB, Leskey TC, RodriguezSaona C, Nielsen AL, Blaauw BR (2017) Chemical ecology of Halyomorpha halys: discoveries and applications. J. Pest Sci., 90: 989-1008.

Wiman NG, Walton VM, Shearer PW, Rondon SI, Lee JC (2015) Factors affecting flight capacity of brown marmorated stink bug, Halyomorpha halys (Hemiptera: Pentatomidae). Journal of Pest Science 88: 37-47. 